\title{
Experimental Investigation into Quasi-Static Crushing of CFRP Composite Cylindrical Tubes after Thermal Aging
}

\author{
Tamer A. Sebaey \\ Engineering Management Department, College of Engineering, \\ Prince Sultan University, Riyadh, Saudi Arabia \\ Mechanical Design and Production Department, Faculty of Engineering, \\ Zagazig University, Zagazig, Sharkia, Egypt \\ sepaey@hotmail.com \& tsebaey@psu.edu.sa
}

\begin{abstract}
For the effective design of polymeric composites, designers need not only to make sure that they meet specific mechanical property criteria but also to consider the impact of environmental factors, which limit the development of safe and economical designs. As one of the expected environmental factors during the composite service life, thermal aging is addressed in the current paper for composite tubes subjected to crushing loading. In the present experimental study, tubes of carbon/epoxy composites were subjected to thermal aging at $90^{\circ} \mathrm{C}, 120^{\circ} \mathrm{C}, 150^{\circ} \mathrm{C}$, and $180^{\circ} \mathrm{C}$ before being subjected to quasi-static crushing. Besides, non-aged specimens were tested for comparison. The results showed that thermal aging has no effects on the load-displacement profile and crushing mode. On the other hand, the crashworthiness, assessed by the peak load, the energy absorbed and the specific energy absorbed, decreased by increasing the aging temperature to $120^{\circ} \mathrm{C}$, due to thermal fatigue of the matrix and the fiber/matrix interface. At $150{ }^{\circ} \mathrm{C}$ (the closest value to the $T_{g}$ ), the crashworthiness improved as a result of the post-curing process. After that temperature, the crashworthiness parameters reduced as a result of chain rupture and matrix oxidation. Based on these results, the designer needs to consider 10-15\% margins in the energy absorption of carbon fiber-reinforced plastic (CFRP) composites to compensate for the thermal aging effect.
\end{abstract}

Keywords: Thermal Aging; CFRP composites; Crushing; Energy Absorption

\section{Introduction}

Nowadays, Fiber Reinforced Polymers (FRPs) are used to produce parts of aircraft, marine, and automotive structures to reduce overall weight, with adequate strength and stiffness, and reduce $\mathrm{CO} 2$ emission as well as improving the fuel efficiency [1]. Energy absorbers are used in automotive mainly to absorb the collision energy in a controlled manner in accidents before transferring it to the passenger compartment, which increases passenger safety. Traditionally, metallic structures have been extensively considered as energy absorbers because of their significant plastic deformation characteristics and capabilities in processing. Nowadays, composites are being used widely in these structures due to its ability to consume the impact energy in different damage mechanisms [2].

Several factors affect the crushing response of FRP composite tubes. These factors include the fiber orientation, the tube geometry, the fiber and matrix material, the crushing speed, the triggering mechanism, the filler, and the impactors' geometry [3]. When exposed to environmental effects, various physical, and chemical reactions may occur in FRP composites, causing degradation of their mechanical, physical and chemical properties [4]. The viscoelasticity of the matrix material substantially influences the temperature dependence of polymeric composites. When the ambient temperature is near/above the glass transition temperature $T_{g}$, the resin matrix softens, transitioning from a glass-like material into a rubber-like material [5]. In this case, the resin matrix cannot provide sufficient stress transfer between the fibers and the matrix, resulting in reduced matrix stiffness and a degraded fiber-matrix interface [6]. In the literature, several authors studied the effect of thermal aging on tensile [6], compression [7], bending [8], and impact [9] properties of FRP composites. To the authors best of knowledge, data available on the crushing after thermal aging of FRP composites is very limited [10]. The aim is to study the effect of thermal aging on the crushing characteristics (both crushing and post-crushing stages) of the CFRP composite tube by the quasi-static axial compression test. 


\section{Material and Test Specimen}

Roll wrapped unidirectional tubes, manufactured by DragonPlate ${ }^{\mathrm{TM}}$, are used in the current analysis. This high strength to weight carbon fiber tubing is fabricated from unidirectional carbon fiber. The layers are oriented to provide high bending stiffness and axial strength and high hoop strength (resistance to crushing from a side load). The composite tube is made of carbon fiber of $2.3 \times 105 \mathrm{MPa}$ elastic modulus and $4800 \mathrm{MPa}$ ultimate strength with a matrix glass transition temperature of $T_{g}=160^{\circ} \mathrm{C}$. The tubes were delivered as one beam of $1200 \mathrm{~mm}$ length, $25.4 \mathrm{~mm}$ inner diameter, and $1.143 \mathrm{~mm}$ wall thickness. Each tube was sliced into the desired specimens' height of $60 \mathrm{~mm}$ using a computercontrolled abrasive cutting machine.

Parts of the tubes were cut and used to estimate the fiber volume fraction. The cut samples were measured (mass and volume) and subjected to ignition, as per the ASTM D3171. After ignition, the fibers remained in the container, where its mass was used to estimate the fiber volume fraction. Five samples were measured using the current methodology, and the result was that the fiber volume fraction $v_{f}=54.1 \%$ with a standard deviation of $2.6 \%$.

\section{Thermal Aging}

The effect of temperature aging on the crushing behavior of composite tubes was studied using an insulated temperature-controlled air oven (JS0F-150) to provide high-temperature environments. Specimens were subjected to a constant temperature for six hours, the constant aging time used for the current study. The aging temperature values were $23{ }^{\circ} \mathrm{C}(\mathrm{RT}), 90{ }^{\circ} \mathrm{C}, 120^{\circ} \mathrm{C}, 150{ }^{\circ} \mathrm{C}$, and $180{ }^{\circ} \mathrm{C}$. It is well-established that the aging temperature effect is highly dependent on the value of the $T_{g}$ [11]. Consequently, the values of the temperatures were selected to have most of the readings before the $T_{g}$ and one reading after the Tg. During its working conditions, composites are usually subjected to temperatures that are mostly below the $T_{g}$. However, in some cases, during its service time, composites can be subjected to temperatures higher than its glass-transition temperature [12]. The mass values of the specimens were measured before and after the thermal exposure, and the values are recorded in Table 1. The values listed in Table 1 are the average per three samples tested at each temperature. The differences in the mass with the different temperature shows an insignificant effect, which can be justified with the short aging time, compared to the data available in the literature [13].

Table 1: Average mass of the CFRP composite tubes before and after the thermal aging.

\begin{tabular}{|c|c|c|c|c|}
\hline \multirow{2}{*}{$\begin{array}{l}\text { Temperature } \\
\left({ }^{\circ} \mathrm{C}\right)\end{array}$} & \multirow{2}{*}{$\begin{array}{l}\text { Mass before } \\
(\mathrm{g})\end{array}$} & \multirow{2}{*}{$\begin{array}{l}\text { Mass after } \\
(\mathrm{g})\end{array}$} & \multicolumn{2}{|c|}{ Difference in mass } \\
\hline & & & Percentage & Standard deviation \\
\hline 90 & 8.77 & 8.73 & 0.4 & 0.08 \\
\hline 120 & 9.03 & 8.99 & 0.37 & 0.05 \\
\hline 150 & 8.14 & 8.11 & 0.37 & 0.01 \\
\hline 180 & 8.08 & 8.05 & 0.37 & 0.12 \\
\hline
\end{tabular}

\section{Quasi-Static Crushing Tests}

Quasi-static crushing tests were performed to assess the crushing capabilities of the composite tubes after thermal aging. The tests were conducted using an Instron 8500 digital testing machine with a full-scale load range of $250 \mathrm{kN}$. Two steel platens were set parallel to each other before starting the test, and the behavior of each specimen under compression was monitored and recorded. The acquisition system of the universal testing machine recorded the loaddisplacement data at a constant cross-head speed of $5 \mathrm{~mm} / \mathrm{min}$ [14]. Three samples were tested for each condition and good agreement between their results were obtained.

The load-displacement data and profile were used to assess the energy absorption [15]. Peak load $P_{i}$ is usually indicated highest point before the post-crushing zone. The mean load $P_{m}$ is the average load during the post crushing stage. The collapsible energy absorption devices must also provide a long deformation path to sufficiently and gradually reduce the deceleration of the protected occupants. Therefore, when evaluating the crashworthiness of an energy absorption device, great attention should be directed to its instantaneous crush force efficiency $C F E$, which is defined as the ratio between $P_{m}$ and $P_{i}$. The energy absorbed $E$ is the force value at each compression distance, which it evaluates 
the area under load-displacement, and is defined as $E=\int P d \delta$. Finally, to access the amount of energy consumed by each unit mass, the specific energy absorbed $\left(E_{S}\right)$ is used. Details on each parameter can be found in [10].

\section{Results and Discussions}

\subsection{Load-displacement and crushing mechanism}

The direct output of the machine is the load-displacement profile. As samples, the data obtained for the specimens at room temperature and at $120^{\circ} \mathrm{C}$ is shown in Figure 1 . Good repeatability is shown in Figure 1, for the same condition. It is worth remarking that the same behavior is shown for the other three test conditions.

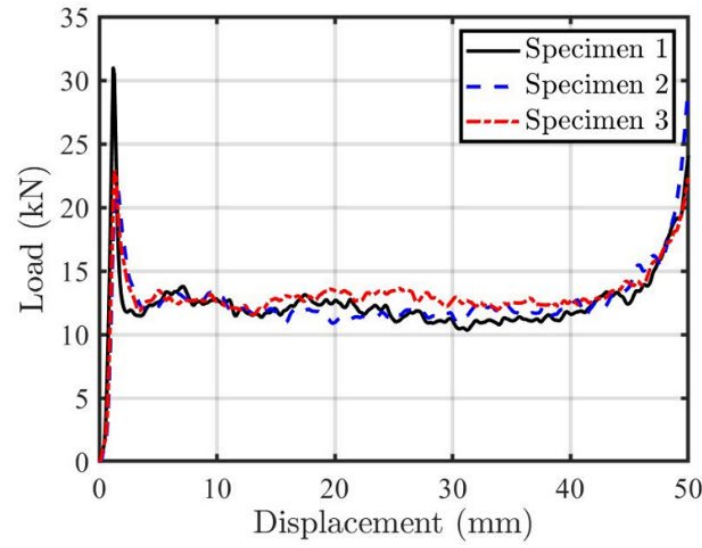

(a)

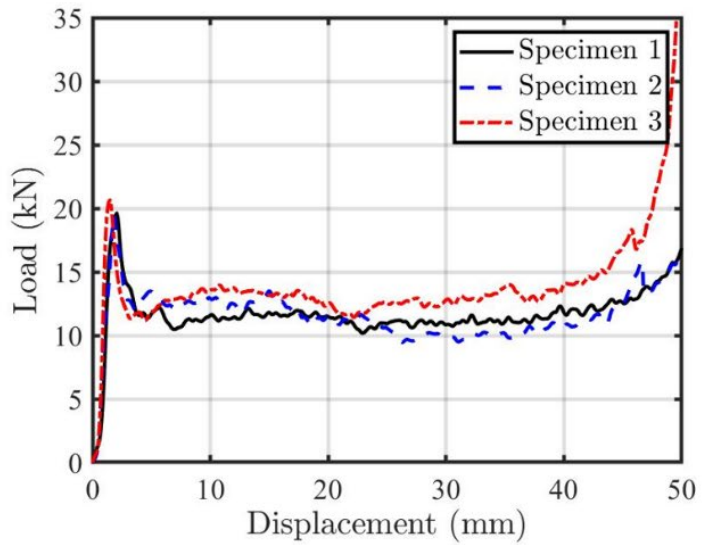

(b)

Fig.1: Load-displacement profile of the specimens (a) without thermal aging and (b) with thermal aging at $120{ }^{\circ} \mathrm{C}$. Three samples are shown for each condition.

The load-displacement profiles in Figure 1 are typical for composite tube subjected to axial crushing, see for example the results in [16]. The first stage is the pre-crushing stage. During this stage, the load-displacement relationship is linear, as it is clear in Figure 1. No visible damage is associated with this pre-crushing stage, Figure 2(i). The end of the first stage is the peak load, after which a drop in the load-carrying capacity of the specimen is recognized. After the peak load, the postcrushing stage starts. On the load-displacement profile, this stage is characterized by several peaks and valleys, with a small amplitude, which indicates a steady-state crushing. On the specimen, Figure 2(ii-vi), this stage is characterized by tearing, fragment, and folding damage. Several authors [17,18] studied the fractography during the post-crushing stage. They concluded that most of the known damage mechanisms (matrix cracking, fiber-matrix debonding, fiber micro buckling, delaminations, and fiber failure) are contributing to the composite tube behavior. This stage continues until the specimen's final densification (at which the specimen is not able to carry any extra load and the stiffness of the machine starts to contribute to the load-displacement profile). The images of the damage propagation and initiation do not show any dependency of the aging temperature. The image of the specimen after crushing shows that the outer layer $\left(0^{\circ}\right)$ experiences longitudinal splitting driven by matrix cracking, and then it is folded outside, Figure 2(vii). The other layers are crushing inward to fill in the internal hole of the tube.

\subsection{Crashworthiness Assessment}

Figure 3 shows the effect of the aging temperature on the load-displacement profile of the CFRP composite tubes. The data is considered for a maximum displacement of $50 \mathrm{~mm}$, for ease comparing the energy absorbed at different temperatures. The load-displacement profile shown in Figure 3 is the mean of three specimens assessed by each condition. The data shows that the highest load-carrying capacity is recorded at RT, as well as at $150{ }^{\circ} \mathrm{C}$. During the post crushing stage, profiles are very similar. In more detail, the peak force $P_{i}$ and the average crushing force $P_{m}$ are shown in Figure 4 . The highest peak 
load is recorded at RT, which decreases by increasing the aging temperature up to $120^{\circ} \mathrm{C}$. At $150{ }^{\circ} \mathrm{C}$, an increase in the peak load is recorded; another decrease follows that. Three different phenomena govern this fluctuation in the loadcarrying capacity.

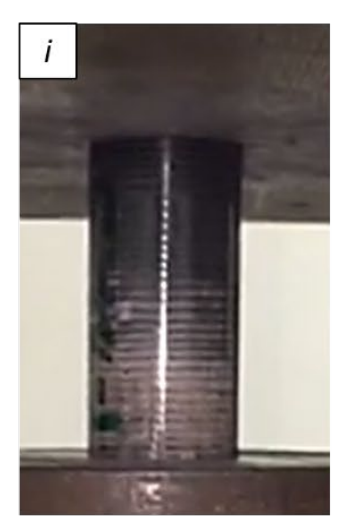

Damage Initiation

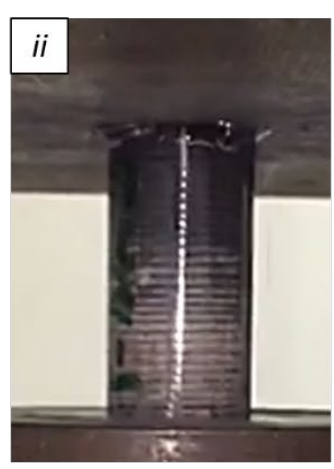

Damage propagation

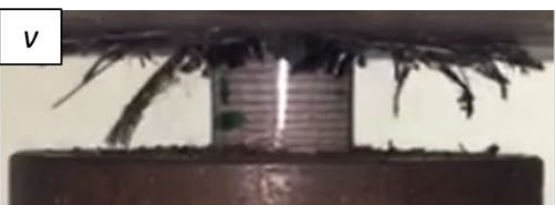

Damage propagation
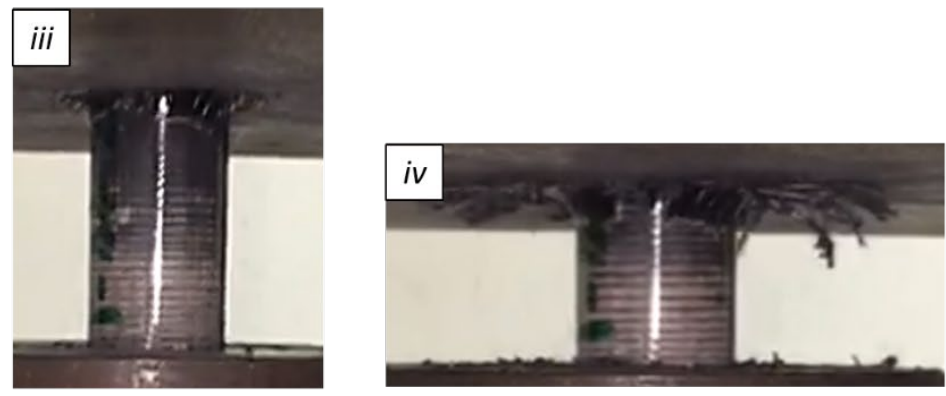

Specimen after crushing

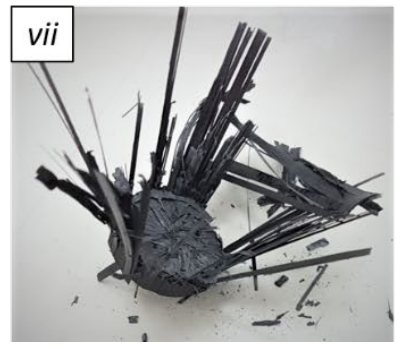

Fig. 2: Crushing mechanism of the CFRP composite tube.

For aging with temperatures much lower than $T_{g}$, thermal fatigue due to the mismatch of the thermal expansion coefficient between the carbon fibers and the epoxy matrix participates to the material degradation [19], which is the responsible of the first degradation in the $P_{i}$ between RT and $120^{\circ} \mathrm{C}$. For aging temperatures close but lower than $T_{g}$, the consolidation phase occurs due to the post-curing reaction that facilitates the adhesion between the fibers and the matrix, maintaining and improving the load-carrying capacity of the composite tube. Similar results were already reported by Garcia-Moreno [20] under impact and bending and by Shaoquan et al. [21] under impact loading. At aging temperatures above $T_{g}$, chemical aging mechanisms, which involve chain rupture, oxidation, and catalytic reaction of gases and pyrolization, occurred [5], which is the responsible of the second degradation in the peak load after $150{ }^{\circ} \mathrm{C}$.

On the other hand, the aging temperature does not show any impact on the average crushing load (the values shown in Figure 4 are the average of three samples). As a result, the crush force efficiency (CFE) increases by decreasing the peak load and vice versa, Table 2. Although it is improving by temperature up to $120{ }^{\circ} \mathrm{C}$, the $C F E$ of the tubes under investigation is still low, compared to the optimal value of $100 \%$. A woven layer on the surface and/or a filler may improve such a parameter, which is beyond the scope of the current study. Similar to the load-carrying capacity, the energy absorbed, Figure 5, and the specific energy absorbed, Table 2, are affected by the chemical changes during the thermal aging. The energy absorbed at room temperature is the highest recorded, which is followed by a reduction in the energy absorbed, up to $120^{\circ} \mathrm{C}$. At $150^{\circ} \mathrm{C}$, the energy absorbed increases due to the post-curing reaction before being decreased after the $T_{g}$. The reduction in the energy absorbed due to the thermal aging from RT to $120{ }^{\circ} \mathrm{C}$ is $10 \%$. On the normalized values $\left(E_{S}\right)$, Table 2 , the maximum reduction is $13.6 \%$. Due to the post-curing process at $150{ }^{\circ} \mathrm{C}$, these composite tubes recover most of its original energy per unit mass $\left(E_{S}\right)$. 


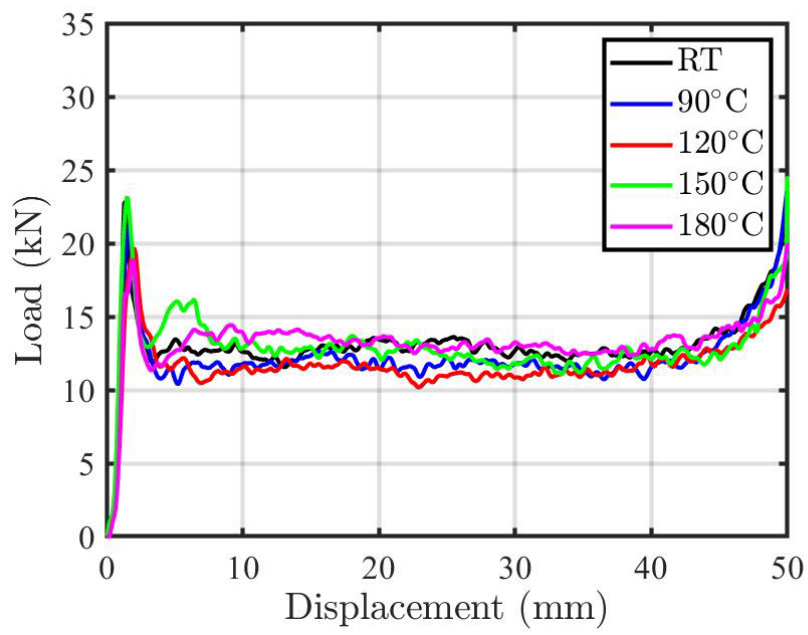

Fig. 3: Summary of the effect of the aging temperature on the load-displacement profile of the CFRP composite tubes.

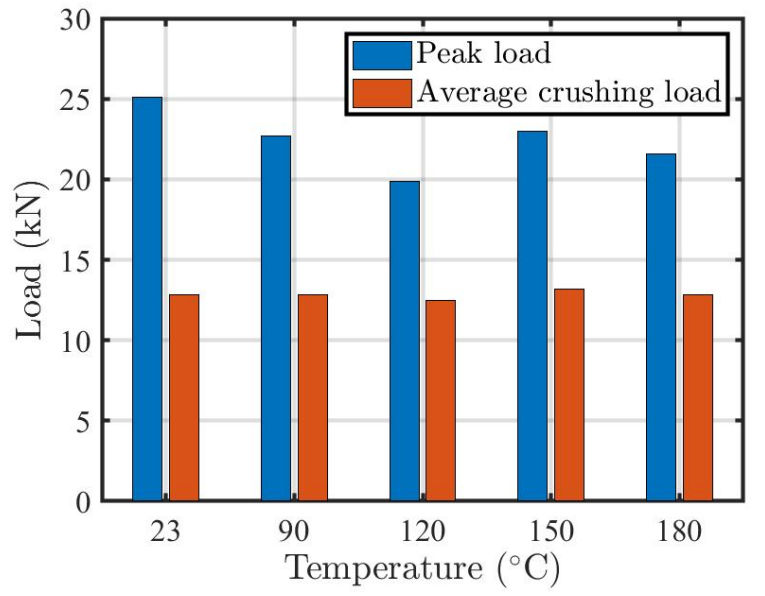

Fig. 4: Peak and average crushing force as functions of the aging temperature.

Table 2: Crush force efficiency CFE and the specific energy absorbed Es of the test campaign at different aging temperature. (CoV is the coefficient of variation of the measurements at each aging temperature)

\begin{tabular}{|l|c|c|c|c|}
\hline \multirow{2}{*}{$\begin{array}{l}\text { Temperature } \\
\left({ }^{\circ} \mathrm{C}\right)\end{array}$} & \multicolumn{2}{|c|}{ Crush force efficiency } & \multicolumn{2}{c|}{ Specific energy } \\
\cline { 2 - 5 } & $\operatorname{CFE}(\%)$ & $\operatorname{CoV}(\%)$ & $E_{S}$ & $\operatorname{CoV}(\%)$ \\
\hline 23 & 52.6 & 10.1 & 80.7 & 8.34 \\
\hline 90 & 57.1 & 8.14 & 72.2 & 8.83 \\
\hline 120 & 62.8 & 3.74 & 69.7 & 15.9 \\
\hline 150 & 58.6 & 8.31 & 50.5 & 1.34 \\
\hline 180 & 61.5 & 14.1 & 78.4 & 4.40 \\
\hline
\end{tabular}




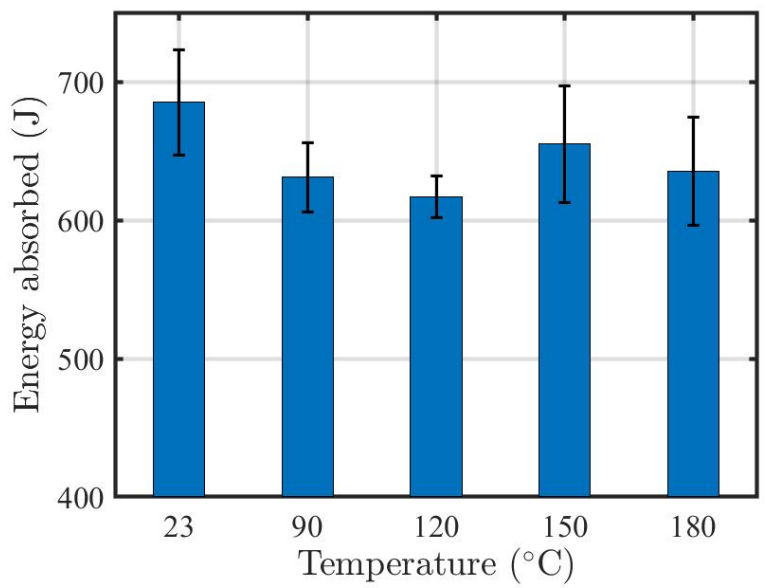

Fig. 5: Energy absorbed $E$ as functions of the aging temperature

In real structure applications, composite tubes can be exposed to air at $-73{ }^{\circ} \mathrm{C}$ to $80{ }^{\circ} \mathrm{C}$ in aerospace whereas, it is exposed to $-140^{\circ} \mathrm{C}$ to $120^{\circ} \mathrm{C}$ in space applications [22]. In automotive, the temperature around the engine and exhaust can exceed the $200{ }^{\circ} \mathrm{C}$ [23]. For light weighting, transportation applications use polymeric fiber-reinforced composites for their structures, with an extra advantage of its crashworthiness. The results obtained in the current study recommended that $10-15 \%$ design margins need to be considered while designing FRP composites to compensate for the temperature aging in real working environment.

\section{Conclusion}

The current paper pretested an experimental study to investigate the effect of thermal aging on the crashworthiness parameters of cylindrical CFRP tubes. The specimens were tested under compression after thermal aging at $90^{\circ} \mathrm{C}, 120^{\circ} \mathrm{C}$, $150^{\circ} \mathrm{C}$, and $180^{\circ} \mathrm{C}$, in addition to tests at room temperature. The peak and average crushing forces, the crush force efficiency, the energy absorbed, and the specific energy were used to assess the composite tubes' crashworthiness.

The results did not show any dependency of the load-displacement profile neither the apparent crushing mechanism on the applied thermal aging. On the other hand, the peak force, the energy, and the specific energy showed degradation by increasing the temperature up to $120^{\circ} \mathrm{C}$, controlled by the matrix cracking and debonding due to thermal mismatch between the fiber and matrix and matrix degradation. At $150{ }^{\circ} \mathrm{C}$, the crashworthiness improved, as a result of the postcuring process of the matrix. At a temperature higher than the $T_{g}\left(\right.$ at $\left.180^{\circ} \mathrm{C}\right)$, the crashworthiness parameters decreased as a result of the chain rupture, oxidation, and catalytic reaction of the matrix.

\section{Acknowledgements}

The author would like to acknowledge the support of Prince Sultan University for covering the conference attendance of this article. In addition, the financial support of the PSU through the S\&M Lab and SEED-PSU-2020-16 is acknowledged.

\section{References}

[1] F. K. Rajak, D. D. Pagar, R. Kumar, C. I. Pruncu, "Recent progress of reinforcement materials: a comprehensive overview of composite materials," J. Mater. Res. Technol., vol. 8, pp. 6354-6374, 2019.

[2] E. Mahdi, T. A. Sebaey, "An experimental investigation into crushing behavior of radially stiffened GFRP composite tubes," Thin-Walled Struct., vol. 76, pp. 8-13, 2014.

[3] E. Mahdi, A. M. S. Hamouda, A. S. Mokhtar, D. L. Majid, "Many aspects to improve damage tolerance of collapsible composite energy absorber devices," Compos. Struct., vol. 67, pp. 175-187, 2005. 
[4] T. Q. Liu, X. Liu, P. Feng, “A comprehensive review on mechanical properties of pultruded FRP composites subjected to long-term environmental effects," Compos. Part B, vol 191, no. 107958, 2020.

[5] M. Leone, S. Matthys, M. A. Aiello, "Effect of elevated service temperature on bond between FRP EBR systems and concrete. Compos. Part B, vol 40, pp. 85-93, 2009.

[6] E. J. Bosze, A. Alawar, O. Bertschger, Y. I. Tsai, S. R. Nutt, "High-temperature strength and storage modulus in unidirectional hybrid composites," Compos. Sci. Technol., vol 66, pp. 1963-1969, 2006.

[7] H. Katoh, T. Ogasawara, S. Sugimoto, T. Ishikawa, "Durability of carbon fiber/epoxy composites under the elevated temperatures," in Proceedings of the 15 $5^{\text {th }}$ Composite Durability Workshop, Kanazawa, JAPAN. 2010.

[8] T. R. Gentry, L.C. Bank, A. Barkatt, L. Prian, "Accelerated test methods to determine the long-term behavior of composite highway structures subject to environmental loading," J. Compos. Technol. Res., vol. 20, pp. 38-50, 1998.

[9] S. Ma, Y. He, L. Hui, L. Xu, "Effects of hygrothermal and thermal aging on the low-velocity impact properties of carbon fiber composites," Adv. Compos. Mater., vol 29, no. 1630054, 2019.

[10] T.A. Sebaey, "Effect of Exposure Temperature on the Crashworthiness of Carbon/Epoxy Composite Rectangular Tubes Under Quasi-Static Compression," Polymers, vol. 12, no. 2028, 2020.

[11] G. M. Odegard, A. Bandyopadhyay, "Physical aging of epoxy polymers and their composites," J. Polym. Sci. Part B, vol. 49, pp. 1695-1716, 2011.

[12] C. Soutis, "Fibre reinforced composites in aircraft construction," Prog. Aeosp. Sci., vol. 41, pp. 143-151, 2005.

[13] P. Alam, C. Robert, C. M. Bradaigh, " Tidal turbine blade composites - A review on the effects of hygrothermal aging on the properties of CFRP," Compos. Part B, vol. 149, pp. 248-259, 2018.

[14] T. A. Sebaey, E. Mahdi, "Crushing behavior of a unit cell of CFRP lattice core for sandwich structures application," Thin-Walled Struct. vol. 116, pp. 91-95, 2017.

[15] T. A. Sebaey, E. Mahdi, A. Shamseldin, E. O. Eltai, " Crushing behavior of hybrid hexagonal/octagonal cellular composite system: All made of carbon fiber reinforced epoxy," Mater. Des., vol. 60, pp. 556-562, 2014.

[16] E. Mahdi, A. M. H. Hamouda, T. A. Sebaey, "The effect of fiber orientation on the energy absorption capability of axially crushed composite tubes," Mater. Des., vol. 56, pp. 923-928, 2014.

[17] R. D. Hussein, D. Ruan, G. Lu, I. Sbarski, "Axial crushing behaviour of honeycomb filled square carbon fibre reinforced plastic (CFRP) tubes,” Compos. Struct., vol. 144, pp. 166-179, 2016.

[18] Y. Wang, J. Feng, J. Wu, D. Hu, "Effects of fiber orientation and wall thickness on energy absorption characteristics of carbon-reinforced composite tubes under different loading conditions. Compos. Struct., vol.153, pp. 356-368, 2016.

[19] L. Olivier, C. Baudet, D. Bertheau, " Development of experimental, theoretical and numerical tools for studying thermo oxidation of CFRP composites," Compos. Part B, vol. 40, pp. 1008-1016, 2009.

[20] I. Garcia-Moreno, M. A. Caminero, G. P. Rodriguez, J. J. Lopez-Cela, "Effect of thermal ageing on the impact damage resistance and tolerance of carbon-fibre-reinforced epoxy laminates," Polymers, vol 11, no. 160, 2019.

[21] W. Shaoquan, D. Shangli, G. Yu, S. Yungang, S, "Thermal ageing effects on mechanical properties and barely visible impact damage behavior of a carbon fiber reinforced bismaleimide composite," Mater. Des., vol 115, pp. 213-223, 2017.

[22] E. Ernault, E. Richaud, B. Fayolle, "Origin of epoxies embrittlement during oxidative ageing," Polym. Test., vol. 63, pp. 448-454, 2017.

[23] P. Merati, C. Davis, K. H. Chen, J. P. Johnson, "Underhood buoyancy driven flow-an experimental study," J. Heat Transfer, vol. 133, no. 082502, 2011. 